\section{Consider alternative causes before allocating acute ischaemic stroke to COVID-19}

We read with interest the excellent article by Dmytriw et al reported on a retrospective, multicenter cohort study of patients with COVID-19 with acute ischaemic stroke (AIS) admitted to stroke units in the USA and Canada between March and August $2020 .^{1}$ The primary endpoint was a modified Rankin Scale (mRS) of 5-6 and the secondary endpoints were an $\mathrm{mRS}<3$, ordinal RS, symptomatic intracerebral haemorrhage and complications during hospitalisation. ${ }^{1}$ It has been established that there may be an association between COVID-19-associated AIS and severe outcome or death, and that the neutrophil to lymphocyte ratio predicts morbidity and mortality. ${ }^{1}$ The study is attractive but raises concerns that need to be discussed.

A limitation of the study is that cardiogenic sources of AIS were not systematically investigated. Echocardiographic findings or long-term ECG recordings are not mentioned for the included patients. Since, COVID-19 infection can be complicated by endocarditis, myocarditis, Takotsubo syndrome (TTS), myocardial infarction or heart failure, ${ }^{2}$ it is crucial that the cardiac cavities and valves are examined for possible adherent or buoyant thrombi. Since COVID-19 can be associated with hypercoagulability, spontaneous thrombus formation within the heart cavities is also possible. TTS has been repeatedly described as a complication of SARS-CoV-2 infections. ${ }^{3}$ Usually, TTS in patients with COVID-19 is due to stress or anxiety. ${ }^{3}$ There are also several reports of endomyocarditis as a complication of SARS-CoV-2 infections. ${ }^{4}$ Patients with endocarditis or myocarditis have an increased risk of thrombus formation and cardioembolism. A patent foramen ovale must be ruled out since COVID-19 can be associated with deep vein thrombosis due to hypercoagulability.
Another limitation of the study is that included patients were not systematically subjected to carotid ultrasound. Since ischaemic stroke can be caused by stenosis or occlusion of the extracranial arteries in $10 \%$ of cases, it is crucial that the included patients have undergone carotid ultrasound or CT angiography of the extracranial arteries.

Another cause of AIS in patients with SARS-CoV-2 is cerebral vasculitis. Cerebral vasculitis is difficult to diagnose because cerebral angiography, cerebrospinal fluid examination and vasculitis parameters may be normal. Occasionally, vasculitis can only be documented by brain biopsy. Reversible cerebral vasoconstriction syndrome as a complication of COVID-19 was also not discussed. It can manifest with headache and AIS.

Venous sinus thrombosis (VST) as a cause of AIS is not considered. Since VST can be a cerebral complication of SARS-CoV-2 infection due to hypercoagulability, it is crucial that all patients in whom the aetiology of AIS remains elusive are screened for VST by CT or MR venography and determination of the D-dimer.

Another limitation of the study is that only fever, cough, shortness of breath, nausea or vomiting, chest pain and sore throat were considered as manifestations of COVID-19. ${ }^{1}$ COVID-19 is a multisystem disease that mainly affects the respiratory system, but the clinical presentation is broader and not limited to the parameters that have been evaluated. Already at the beginning of the disease, COVID-19 can manifest itself with a number of extrapulmonary manifestations. ${ }^{5}$ Because of this, some patients with AIS and COVID-19 may have been missed.

Overall, the interesting study has some limitations that call into question the results and their interpretation. Multiple causes of AIS in SARS-CoV-2-infected patients have not been considered as differential causes of AIS. Allocation of AIS to COVID-19 is only permitted after alternative causes of AIS have been ruled out.

\section{Josef Finsterer $\odot$}

Neurology \& Neurophysiology Center, Vienna, Austria

Correspondence to Dr Josef Finsterer, Neurology \& Neurophysiology Center, 1180 Vienna, Austria; fifigs1@ yahoo.de

Contributors The author was resposible for all required issues.

Funding The author has not declared a specific grant for this research from any funding agency in the public, commercial or not-for-profit sectors.

Competing interests None declared.

Patient consent for publication Not applicable.

Ethics approval This study does not involve human participants.

Provenance and peer review Not commissioned; internally peer reviewed.

(C) Author(s) (or their employer(s)) 2022. No commercial re-use. See rights and permissions. Published by BMJ.

\section{Check for updates}

To cite Finsterer J. J Neurol Neurosurg Psychiatry Epub ahead of print: [please include Day Month Year]. doi:10.1136/jnnp-2022-329029

Received 8 February 2022

Accepted 11 February 2022

J Neurol Neurosurg Psychiatry 2022;0:1. doi:10.1136/jnnp-2022-329029

\section{ORCID iD}

Josef Finsterer http://orcid.org/0000-0003-2839-7305

\section{REFERENCES}

1 Dmytriw AA, Dibas M, Phan K, et al. Acute ischaemic stroke associated with SARS-CoV-2 infection in North America. J Neurol Neurosurg Psychiatry 2022;2. doi:10.1136/jnnp-2021-328354. [Epub ahead of print: 25 Jan 2022].

2 Crudo VL, Ahmed Al, Cowan EL, et al. Acute and subclinical myocardial injury in COVID-19. Methodist Debakey Cardiovasc J 2021;17:22-30.

3 John K, Lal A, Mishra A. A review of the presentation and outcome of takotsubo cardiomyopathy in COVID-19. Monaldi Arch Chest Dis 2021;91.

4 Ouarradi AE, Kantri A, Agrad K, et al. Infective endocarditis following COVID-19 pneumonia: about two cases. Pan Afr Med J 2021:40:152.

5 Finsterer J, Scorza FA, Scorza CA, et al. Extrapulmonary onset manifestations of COVID-19. Clinics 2021;76:e2900 